\title{
IMPLEMENTACIÓN DE UN SISTEMA DE CALEFACCIÓN SOLAR TÉRMICO: ANÁLISIS ENERGÉTICO Y ECONÓMICO
}

\author{
Juan Pablo Vargas Bautista, Pablo Yampasi Espejo, Xerxes Tirado Villarroel y Andrés Patzi
}

\section{RESUMEN}

El siguiente trabajo presenta la implementación de un sistema de calefacción solar térmico que usa tubos al vacío para el calentamiento de un fluido térmico, aprovechando la energía solar como fuente primaria de energía. La energía almacenada en el fluido es utilizada para climatizar un ambiente de una superficie de $45.5 \mathrm{~m}^{2}$. El sistema se desarrolló con el objetivo de determinar la factibilidad tanto técnica como económica para su implementación en regiones de clima frío en Bolivia. El sistema cuenta con un colector solar de tubos al vacío que se conecta mediante tuberías a un intercambiador de calor tipo radiador. Se usó una bomba para la circulación del fluido caliente del colector al radiador y un ventilador para acelerar la transferencia de calor en el ambiente a climatizar. El sistema de calefacción cuenta con un termostato para el control de la temperatura ambiente para optimizar la energía solar disponible y el consumo de energía eléctrica de la bomba de agua y ventilador de aire. Con la implementación del sistema de calefacción, se consiguió aumentar la temperatura del ambiente de prueba a la temperatura deseada en 3 horas de funcionamiento, en el tiempo restante, el colector solar térmico almacenó la energía solar disponible en el tanque de agua para usarlo al día siguiente. Se comparó el sistema de calefacción solar con un calefactor eléctrico (4 $\mathrm{kW}$ ) bajo las mismas condiciones de operación. Se estimó un ahorro en energía eléctrica mensual de $163.1 \mathrm{kWh} / \mathrm{mes}$ con el sistema de calefacción solar que se traduce a un ahorro económico estimado de 23.4 \$US/mes. Al reducir el consumo de energía eléctrica también se reduce la emisión de gases de efecto invernadero (G.E.I.) en $81.5 \mathrm{~kg}$ de $\mathrm{CO}_{2} /$ mes. Para el presente caso de estudio, el tiempo en el que se puede recuperar la inversión del sistema de calefacción solar térmico respecto al calefactor eléctrico es de 5.3 años. Como un parámetro importante se tiene que un metro de colector solar térmico de tubo al vacío puede calentar un ambiente de $16.5 \mathrm{~m}^{2}$.

Palabras Clave: Calefacción Solar Térmica, Energías Solar Térmica, Eficiencia Energética, Tecnologías Sustentables. 